\title{
Cefpirome Sulfate
}

National Cancer Institute

\section{Source}

National Cancer Institute. Cefpirome Sulfate. NCI Thesaurus. Code C87463.

The sulfate form of cefpirome, a semisynthetic, broad-spectrum, fourth-generation cephalosporin with antibacterial activity. Cefpirome binds to and inactivates penicillinbinding proteins (PBPs) located on the inner membrane of the bacterial cell wall. PBPs are enzymes involved in the terminal stages of assembling the bacterial cell wall and in reshaping the cell wall during growth and division. Inactivation of PBPs interferes with the cross-linkage of peptidoglycan chains necessary for bacterial cell wall strength and rigidity. This results in the weakening of the bacterial cell wall and causes cell lysis. 